\title{
Modulation of the Isoprenoid/Cholesterol Biosynthetic Pathway During Neuronal Differentiation In Vitro
}

\author{
Veronica Cartocci, ${ }^{1}$ Marco Segatto, ${ }^{2}$ Ilenia Di Tunno, ${ }^{1}$ Stefano Leone, ${ }^{1}$ \\ Frank W. Pfrieger, ${ }^{3}$ and Valentina Pallottini ${ }^{1 *}$ \\ ${ }^{1}$ Department of Science, Biomedical and Technology Science Section, University Roma Tre, Viale Marconi, 446, \\ 00146, Rome, Italy \\ ${ }^{2}$ Department of Biosciences, University of Milan, Via Giovanni Celoria, 26, 20133, Milan, Italy \\ ${ }^{3}$ Institute of Cellular and Integrative Neurosciences (INCI) CNRS UPR 3212, University of Strasbourg, 5 rue Blaise \\ Pascal, 67084, Strasbourg, France
}

\begin{abstract}
During differentiation, neurons acquire their typical shape and functional properties. At present, it is unclear, whether this important developmental step involves metabolic changes. Here, we studied the contribution of the mevalonate (MVA) pathway to neuronal differentiation using the mouse neuroblastoma cell line N1E-115 as experimental model. Our results show that during differentiation, the activity of 3-hydroxy 3-methylglutaryl Coenzyme A reductase (HMGR), a key enzyme of MVA pathway, and the level of Low Density Lipoprotein receptor (LDLr) decrease, whereas the level of LDLr-related protein-1 (LRP1) and the dimerization of Scavanger Receptor B1 (SRB-1) rise. Pharmacologic inhibition of HMGR by simvastatin accelerated neuronal differentiation by modulating geranylated proteins. Collectively, our data suggest that during neuronal differentiation, the activity of the MVA pathway decreases and we postulate that any interference with this process impacts neuronal morphology and function. Therefore, the MVA pathway appears as an attractive pharmacological target to modulate neurological and metabolic symptoms of developmental neuropathologies. J. Cell. Biochem. 117: 20362044, 2016. ๑) 2016 Wiley Periodicals, Inc.
\end{abstract}

KEY WORDS: 3-HYDROXY 3-METHYLGLUTARYL COENZYME A REDUCTASE; CHOLESTEROL; ISOPRENOID; LIPOPROTEIN RECEPTORS; N1E-115; NEURONAL DIFFERENTIATION

$\mathrm{T}$ he differentiation of neurons is a decisive phase during brain development, which spans weeks in rodents and years in humans. Newly generated neurons acquire their cell-type specific shape and functional properties [da Silva and Dotti, 2002]. They grow axons and dendrites, they establish synaptic connections and they express transmitter receptors and ion channels that determine the cell-specific firing patterns [Hanson and Landmesser, 2004]. The function of the adult brain depends critically on the correct execution of these developmental events. Interference with neuronal differentiation due to genetic factors, drug treatment or environmental factor exposure can provoke late neurologic or psychiatric symptoms [Chaudhury et al., 2015; Hill et al., 2015; Nuttall, 2015]. For example, valproic acid treatment or bacterial infections during pregnancy can cause autism in offspring [Jensen, 1994]. Mutations in methyl-CpG-binding protein-2 (mecp2) cause Rett syndrome, a neurodevelopmental disorder [Amir et al., 1999].

A major goal is to identify the metabolic pathways that are decisive for neuronal differentiation and that are potentially implied in disease mechanisms. Here, we focused on the ubiquitously expressed mevalonate (MVA) pathway (Fig. 1). Its end products (e.g., coenzyme Q10, prenyls, and cholesterol) are essential for neuronal function [Lee et al., 2014; Segatto et al., 2014a; Villarroel-Campos et al., 2014]: cholesterol, for example, is a key component of the myelin sheath and of neuronal membranes in axons, dendrites, and synapses [Orth and Bellosta, 2012]. It must be synthesized within the brain as the blood-brain barrier prevents import of lipoproteins, but the cellular origin of the different pools in neurons are incompletely understood

Conflict of interest: Authors declare no conflict of interest.

Veronica Cartocci and Marco Segatto contributed equally to this work.

Grant sponsor: University of "Roma Tre”; Grant number: CLA 2013-2015.

*Correspondence to: Valentina Pallottini, Department of Science, Biomedical and Technology Science Section,

University Roma Tre, Viale Marconi, 446, 00146, Rome, Italy. E-mail: valentina.pallottini@uniroma3.it

Manuscript Received: 22 January 2016; Manuscript Accepted: 25 January 2016

Accepted manuscript online in Wiley Online Library (wileyonlinelibrary.com): 27 January 2016

DOI 10.1002/jcb.25500 • (C) 2016 Wiley Periodicals, Inc. 


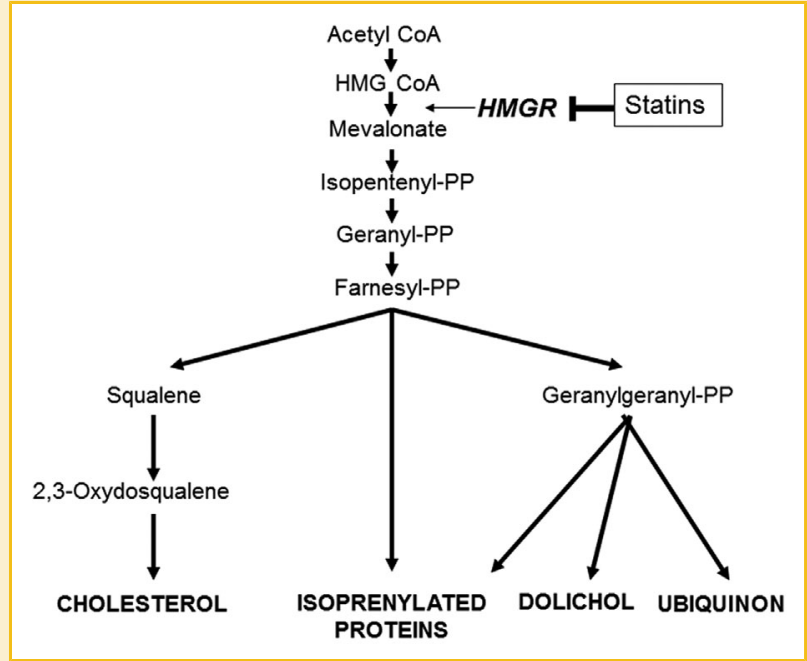

Fig. 1. Schematic representation of the mevalonate pathway.

[Pfrieger and Ungerer, 2011; Segatto et al., 2014a]. A perturbation of cholesterol homeostasis can cause neurologic and psychiatric symptoms and contribute to diseases like RETT syndrome [Buchovecky et al., 2013; Martin et al., 2014; Segatto et al., 2014c], Huntington disease [Valenza et al., 2015] or autism [Wang, 2014]. Besides cholesterol, isoprenoids play significant roles in the CNS. The post-translational binding of farnesyl pyrophosphate (FPP) or of geranylgeranyl pyrophosphate (GGPP) moieties to proteins is critical for protein localization and, in turn, for cell maturation and growth [Prendergast and Oliff, 2000; Sah et al., 2000].

A key enzyme of the MVA pathway is 3-hydroxy-3-methylglutaryl coenzyme A reductase (HMGR), which catalyses the production of MVA [Brown and Goldstein, 1980; Segatto et al., 2014b]. Its activity is regulated within minutes by phosphorylation and dephosphorylation through AMP activated enzyme (AMPK) and Protein Phosphatase 2A (PP2A), respectively [Pallottini et al., 2007], and within hours by transcriptional changes through the Sterol Regulatory Element Binding Proteins (SREBPs) [Espenshade and Hughes, 2007]. The enzyme is efficiently inhibited by statins, a group of drugs that are commonly used to treat hypercholesteremia [Trapani et al., 2011]. Statin treatment of humans and rodents impacts the adult brain and affects emotion, learning, and memory processes [Baytan et al., 2008; While and Keen, 2010; Douma et al., 2011; Kilic et al., 2012; Segatto et al., 2014b]. The effects of statins on the developing brain are less clear. Previous studies investigated how statins affect neuronal differentiation in vitro [Maltese and Sheridan, 1985; Fan et al., 2002; Schulz et al., 2004; Kim et al., 2009; Raina et al., 2013; Samuel et al., 2014], but the results vary depending on the experimental protocols and the statins used. Moreover, it is unclear, whether neuronal differentiation modulates the mevalonate pathway per se. We addressed these questions using a mouse neuroblastoma cell line as experimental model permitting DMSO-induced differentiation [Shim et al., 2006].

\section{CHEMICALS AND ANTIBODIES}

Unless indicated otherwise, all materials were from Sigma-Aldrich (St. Louis, M0). Geranylgeraniol was a generous gift of Prof. Ewa Sviezewszka (Polish Academy of Science, Warsaw, Poland). For immunoblotting, antibodies against the following proteins were used: P-AMPK $\alpha$ and AMPK $\alpha$ (Cell Signalling Technology, Boston, MA), PP2A (catalytic sub-unit), RhoA, LRP1, and SREBP-1 (Santa Cruz Biotechnology, Santa Cruz, CA), LDLr (ab30532 and SREBP-2 (Abcam, Cambridge, United Kingdom), P-HMGR (Millipore, Temecula, CA), HMGR (Upstate, Lake Placid, NY), SRB-1 (Novus Biological, Littleton, CO). $\alpha$-Tubulin (Sigma-Aldrich) or caveolin (Santa Cruz, CA) were used as loading controls . HRP-conjugated IgG produced in mouse or in rabbit used as secondary antibodies were obtained from Biorad Laboratories (Milan, Italy).

\section{CELL CULTURE}

Mouse neuroblastoma clone N1E-115 was obtained from the European Collection of Cell Cultures (Cat. no. 88112303) (Salisbury, United Kingdom). Cells were grown in Dulbecco's modified Eagle's medium (DMEM) containing $4500 \mathrm{mg} / \mathrm{L}$ glucose, $2 \mathrm{mM}$ L-glutamine, 10\% fetal bovine serum (FBS), penicillin and streptomycin (Lonza, Milano, Italia) in a humidified incubator with $5 \% \mathrm{CO}_{2}$ at $37^{\circ} \mathrm{C}$.

\section{NEURONAL DIFFERENTIATION}

N1E-115 cells were plated for $5 \mathrm{~h}$ in DMEM medium (GIBCO) 10\% serum to allow cell adhesion. Neuronal differentiation was induced by the addition of $2 \%$ dimethylsulfoxide (DMSO). The medium containing DMSO was changed on day 3 and neuronal differentiation was observed up to $120 \mathrm{~h}$ in the differentiation medium. For experimental treatments, cultures were incubated in the presence of differentiation medium supplemented with Ethanol (Et-OH) as control or with Simvastatin (Sim). In addition, culture dishes were treated with different products of the MVA pathway: Cholesterol (CHOL), Farnesol (Far), Geranylgeraniol (GG) in the presence or absence of Simvastatin. These pharmacological agents were used at a concentration of $1 \mu \mathrm{M}$ dissolved in ET-OH.

\section{NEURITE EXTENSION ASSAY}

The degree of differentiation was evaluated based on the length of neuritic processes in different directions and at different time intervals $(16,24,48,72$, and $120 \mathrm{~h})$ using an Olympus CKX 41 microscope equipped with a Leica DFC 420 camera. Electronic images were further processed using Adobe Photoshop CS2.

For each treatment, 10 randomly selected fields from three independent preparations were analyzed.

While small and spherical in their undifferentiated state, morphologically transformed N1E-115 cells are typically $40 \mu \mathrm{m}$ or larger and extend processes which often span several hundred micrometer. The neurite length was evaluated with ImageJ software for Windows (NIH, Bethesda, MD) and was reported as arbitrary units. Only neuritic processes that were longer than two times the diameter of the cell were considered. 


\section{XTT ASSAY}

Cell viability was detected by the XTT assay following manufacturer instructions (Cell Signalling Technology; Boston, MA). This assay detects a formazan dye produced from XTT conversion by mitochondrial enzymes. $5 \times 10^{3}$ cells were plated in 96 well dishes. Cells were treated with $2 \%$ DMSO in presence and in absence of $1 \mu \mathrm{M}$ simvastatin for $120 \mathrm{~h}$ using ET-OH as control.

\section{FLOW CYTOMETRY ANALYSIS}

To evaluate cell viability, $1.5 \times 10^{5} \mathrm{~N} 1 \mathrm{E}-115$ cells were grown in $3.5 \mathrm{~cm}$ Petri dish in DMEM medium (GIBCO) with 10\% FBS and treated with $2 \%$ DMSO in the presence of $1 \mu \mathrm{M}$ simvastatin or of ET-OH alone $(0.1 \% \mathrm{v} / \mathrm{v})$ for $120 \mathrm{~h}$. After trypsin detach, cells were treated with propidium iodide (PI) $(2 \mu \mathrm{g} / \mathrm{ml})$ and immediately analyzed by flow cytometry. For each experiment, 20,000 events on were acquired and the percentage of live cells was calculated by design an electronic gate on PI negative events. To stain SR-B1 on the live cell surface, $1.5 \times 10^{5}$ cells were seeded into $3,5 \mathrm{~cm}$ Petri dish on DMEM supplemented with 10\% FBS for each experimental point.
After $5 \mathrm{~h}$, medium was replaced by fresh complete medium containing $2 \%$ DMSO or ET-OH. For each time point $\left(t_{0}, t_{72}\right)$, cells were harvested with trypsin and washed twice with cold phosphate buffered saline (PBS) containing 5\% BSA. For each sample, living cells were incubated with anti-SR-B1 (for $30 \mathrm{~min}$ at $4^{\circ} \mathrm{C} ; 1: 100$ in PBS/5\% BSA; Novus Biological). Samples were incubated with FITC-conjugated goat anti-rabbit secondary antibody (30 min at $4^{\circ} \mathrm{C}$; 1:100 PBS/5\% BSA; Cappel). Background controls with secondary antibody alone were included at each time point. Immunofluorescence intensity was measured by a Galaxy flow cytometer (DakoCytomation) and analyzed by Flowjo v.5.4.4 software (Tree Star Inc., Ashland, OR). For each sample, 20,000 events were recorded, data were obtained from three independent experiments. Dead cells were omitted from analysis by side scatter electronic gate exclusion.

\section{WESTERN BLOTTING ANALYSIS}

To prepare total protein lysate, N1E-115 cells were washed at indicated times with $1 \mathrm{ml}$ of phosphate buffered saline

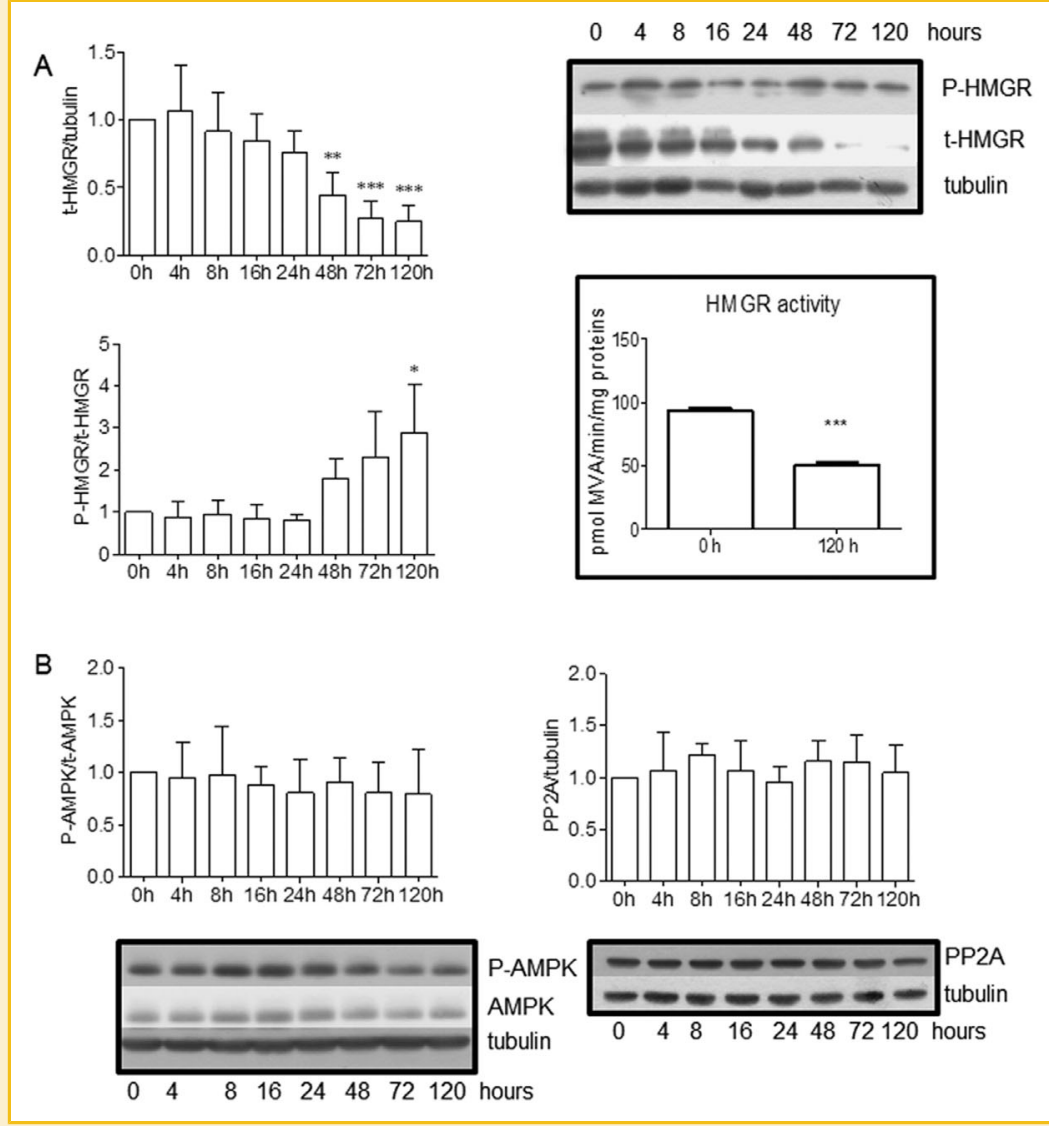

Fig. 2. HMGR, $A M P K$, and PP2A analysis in differentiating N1E-115 mouse neuroblastoma. Panel $A$ illustrates HMGR analysis. On the left the densitometric analyses of total protein content (up) and the phosphorylation state of the enzyme (bottom), quantified as t-HMGR/tubulin and P-HMGR/t-HMGR, respectively. A representative Western blot is shown on the right (up). The size of HMGR is $90 \mathrm{kDa}$, the size of tubulin is $50 \mathrm{kDa}$. ${ }^{* *} P<0.01,{ }^{* * *} P<0.001$ versus $0 \mathrm{~h}$ as from one-way analysis of variance (ANOVA) followed by Tukey post-test. Inset illustrates HMGR activity measured as pmol of $\left[{ }^{14} \mathrm{C}\right]-\mathrm{MVA}$ production/min/mg proteins at $0 \mathrm{~h}$ and $120 \mathrm{~h}$ after the induction of differentiation by using $2 \%$ DMSO. ${ }^{* *} P<0.001$ versus $0 \mathrm{~h}$ as from a Student's $t$-test. Panel B illustrates AMPK (left) and PP2A catalytic sub-unit (right) analysis. On the bottom are represented the immunoblots from representative experiments. Average protein expression is quantified as P-AMPK/AMPK, and PP2A/tubulin (right graph). The size of AMPK is 68 kDa, The size of the catalytic subunit of PP2A is $35 \mathrm{kDa}$, the size of tubulin is $50 \mathrm{kDa}$. All the presented data derives from three independent experiments, for details see the main text. 
(PBS; $\mathrm{PH}=7.4)$, trypsinized $\left(2 \mathrm{~min}\right.$ at $\left.37^{\circ} \mathrm{C}\right)$, harvested, centrifuged (1 min at 13,000 rpm at room temperature), resuspended and sonicated (30 s) in $50 \mu \mathrm{l}$ of sample buffer containing $0.125 \mathrm{M}$ TrisHCL pH 6.8, 10\% SDS, $0.062 \mathrm{M} \mathrm{NaF}$ and Protease Inhibitor Cocktail (Sigma).

To prepare the membrane fraction, cells were homogenized in a homogenization buffer (0.01 M Tris- $\mathrm{HCl}, 0.001 \mathrm{M} \mathrm{CaCl}_{2}, 0.15 \mathrm{M}$ $\mathrm{NaCl}, 0.001 \mathrm{M}$ PMSF, $\mathrm{pH}$ 7.5) and spun down $(10,000 \mathrm{~g}$ for $10 \mathrm{~min})$. The supernatant was centrifuged two times $(100,000 \mathrm{~g}$ for $45 \mathrm{~min}$ ), the pellet containing the membrane fraction was solubilized $(0.125 \mathrm{M}$ Tris- $\mathrm{HCl}-\mathrm{pH}$ 6.8- containing 10\% SDS, $0.001 \mathrm{M}$ PMSF) and the protein concentration was measured [Lowry et al., 1951]. Membrane and total lysate samples were boiled for $3 \mathrm{~min}$ before SDS-PAGE and subsequent Western blotting. The presence of caveolin (membrane marker) and $\alpha$-tubulin (cytosolic marker) confirmed the purity of the membrane fractions (data not shown). All experiments were carried out in triplicate.

Thirty micrograms of protein were separated by SDS-PAGE and blotted to nitrocellulose membranes (Trans-blott Turbo, BioRad). Immunoblots were incubated with primary antibodies $(1: 1,000)$ followed by secondary peroxidase-conjugated antibodies $(1: 10,000$; Biorad). Immunoreactivity was detected by enhanced chemiluminescence (GE Healthcare, Little Chalfont, United Kingdom). All images derived from Western blotting were analyzed with ImageJ (National Institutes of Health, Bethesda, MD). Intensity values of

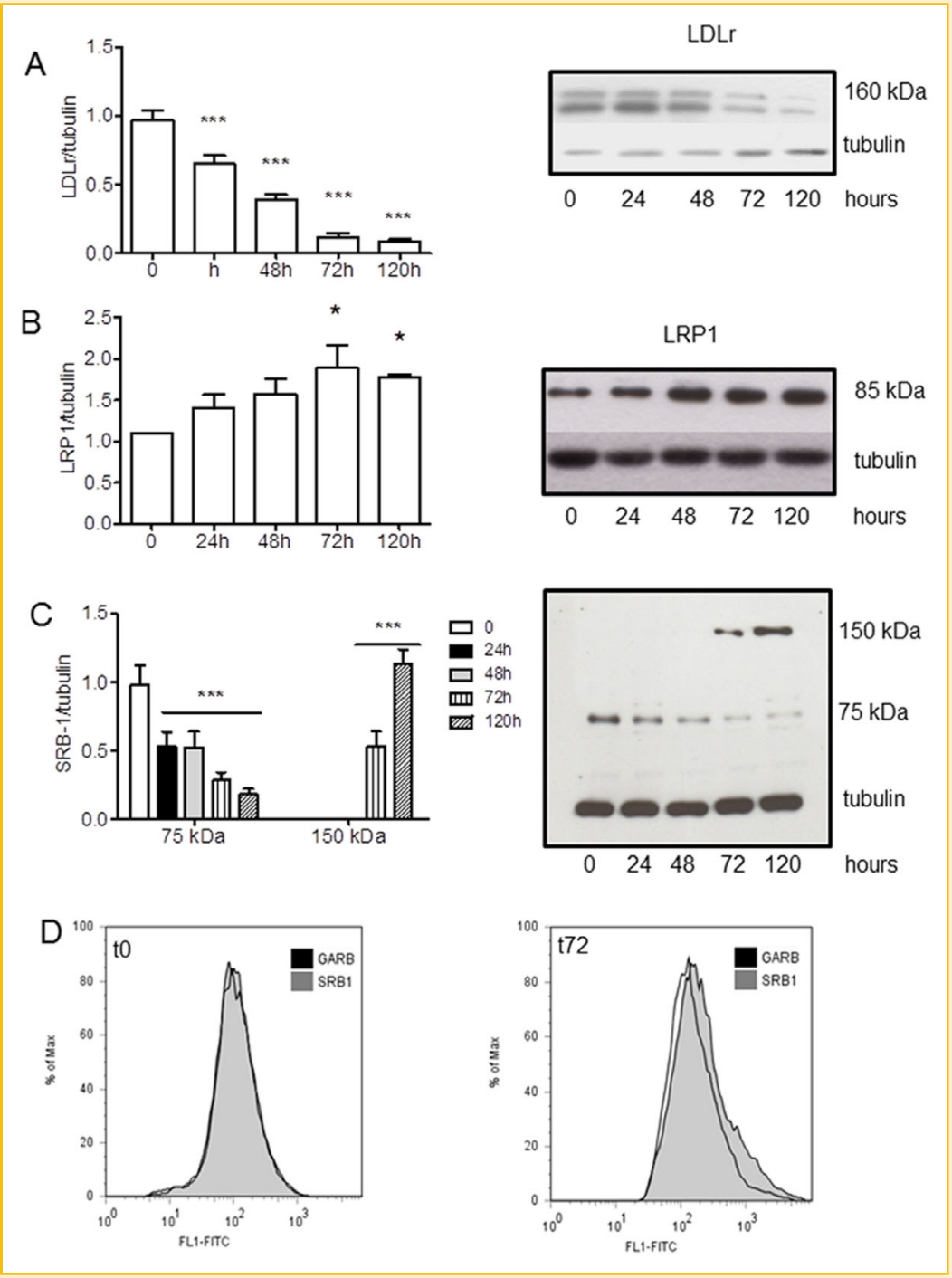

Fig. 3. LDLr, LRP1, and SR-B1 analysis in differentiating N1E-115 mouse neuroblastoma. Panel A illustrates LDLr analysis, Panel B illustrates LRP1 analysis, and Panel C illustrates SRB-1 analysis. On the right are represented the immunoblots from representative experiments. Average protein expression is represented on the left and quantified as ratio between protein and tubulin. ${ }^{*} P<0.05$, ${ }^{* * *} P<0.001$ versus $0 \mathrm{~h}$ as from one-way analysis of variance (ANOVA) followed by Tukey post-test. Panel $D$ shows membrane expression of SRB-1 receptor on live cells before and after $72 \mathrm{hr}$ of DMSO-induced differentiation. The results are presented as cytometric histograms distribution (goat antirabbit FITC conjugated control stain [black], versus surface anti-SRB-1 antibody [gray]). These results are representative of three similar experiments. 
selected proteins were normalized to intensities of respective housekeeping proteins (tubulin or caveolin).

\section{HMGR ACTIVITY ASSAY}

Activity was measured using a radioisotopic assay based on the production of ${ }^{14} \mathrm{C}-\mathrm{MVA}$ (mevalonate) from 3-[ $\left.{ }^{14} \mathrm{C}\right]-\mathrm{HMGCoA}$ (specific activity $57.0 \mathrm{mCi} / \mathrm{mmol}$. Amersham-Pharmacia, Little Chalfont, UK). N1E-115 cells were differentiated with 2\% DMSO for $120 \mathrm{~h}$ in the presence of $1 \mu \mathrm{M}$ simvastatin or of ET-OH. Cells were homogenized in phosphate buffer $(0.1 \mathrm{M}$ sucrose, $0.05 \mathrm{M} \mathrm{KCl}$, $0.04 \mathrm{M}$ KH2P04, $0.03 \mathrm{M}$ EDTA, $50 \mathrm{mM} \mathrm{NaF}, \mathrm{pH}$ 7.4) and incubated in the presence of co-factors $(20 \mathrm{mM}$ glucose-6-phosphate, $20 \mathrm{mM}$ NADP sodium salt, 1 unit of glucose-6-phosphate dehydrogenase, and $5 \mathrm{mM}$ dithiothreitol) in a final volume of $190 \mathrm{ml}$ (for $100 \mu \mathrm{g}$ protein). The assay was started by addition of $10 \mu \mathrm{l}$ 3- $\left[{ }^{14} \mathrm{C}\right]$-HMG-CoA (0.088 $\left.\mathrm{mCi} / 11.7 \mathrm{nmol}\right)$. The synthesized $\left[{ }^{14} \mathrm{C}\right]-$ MVA was purified by chromatography (AG1-X8 ion exchange resin; BioRad, Italy) and the radioactivity measured (Liquid Scintillator Analyzer, Perkin Elmer). The recovery was calculated based on an internal standard $\left(3-\left[{ }^{3} \mathrm{H}\right]-\mathrm{MVA}\right.$, specific activity 24.0 $\mathrm{Ci} / \mathrm{mmol}$ (Amersham-Pharmacia, Little Chalfont, United Kingdom).

\section{FILIPIN STAINING}

$5 \times 10^{3}$ cells were seeded, into 96 wells plate (Falcon black/clear tissue culture treated plate flat bottom) and after adhesion ( $5 \mathrm{~h}$ ) the medium was changed with complete medium in presence of 2\% DMSO with or without $1 \mu \mathrm{M}$ of Simvastatin. The medium was changed with fresh stimuli each 2 days and cells were cultured for $120 \mathrm{~h}$. To visualize the intracellular cholesterol distribution, cultured cells were fixed (4\% paraformaldehyde for $15 \mathrm{~min}$ ) and incubated for $2 \mathrm{~h}$ with filipin $(10 \mu \mathrm{g} / \mathrm{ml}$ with $0.1 \%$ ethanol, Sigma). Filipin fluorescence was imaged on an inverted microscope (Axiovert 135TV; Zeiss) equipped with a metal halide lamp (10\%; Lumen 200; Prior Scientific), an appropriate excitation/emission filter (XF02-2; Omega Optical Inc.), a 40× objective (N.A. 1.3; Zeiss) and an air-cooled monochrome CCD camera (Sensicam, PCO Computer Optics) controlled by custom-written Labview routines (National Instruments).

Data analysis was performed with ImageJ (National Institutes of Health, Bethesda, MD) software for Windows. The experiment was performed with four biological replicates. For each experimental group 10 randomly selected fields were analyzed.

\section{STATISTICAL ANALYSIS}

Data were analyzed by Student's t-test in the case of two experimental conditions and by one-way analysis of variance (ANOVA) followed by Tukey post-test for multiple conditions (GraphPad Instat3; GraphPad, Inc., La Jolla, CA).

\section{RESULTS}

We investigated the role of the MVA pathway during neuron differentiation using the N1E-115 cell line [Shim et al., 2006]. To avoid confounding effects of serum and thus cholesterol deprivation we induced neuronal differentiation by DMSO [Clejan et al., 1996; Rodrigues et al., 2005; Oh et al., 2006]. As a first step, we investigated whether DMSO affected HMGR, a key component of the MVA pathway. Indeed, as shown in Figure 2A, the amount of total HMGR protein in neurons decreased and the fraction of phosphorylated protein increased during differentiation. The levels of enzymes that regulate the phosphorylation status of HMGR, AMPK, and PP2A, were stable during $120 \mathrm{~h}$ of treatment (Fig. 2B). The observed changes in HMGR suggested that the level of the enzyme decreases during DMSO-induced differentiation. Indeed, metabolic labeling of mevalonate revealed that its activity was significantly reduced after
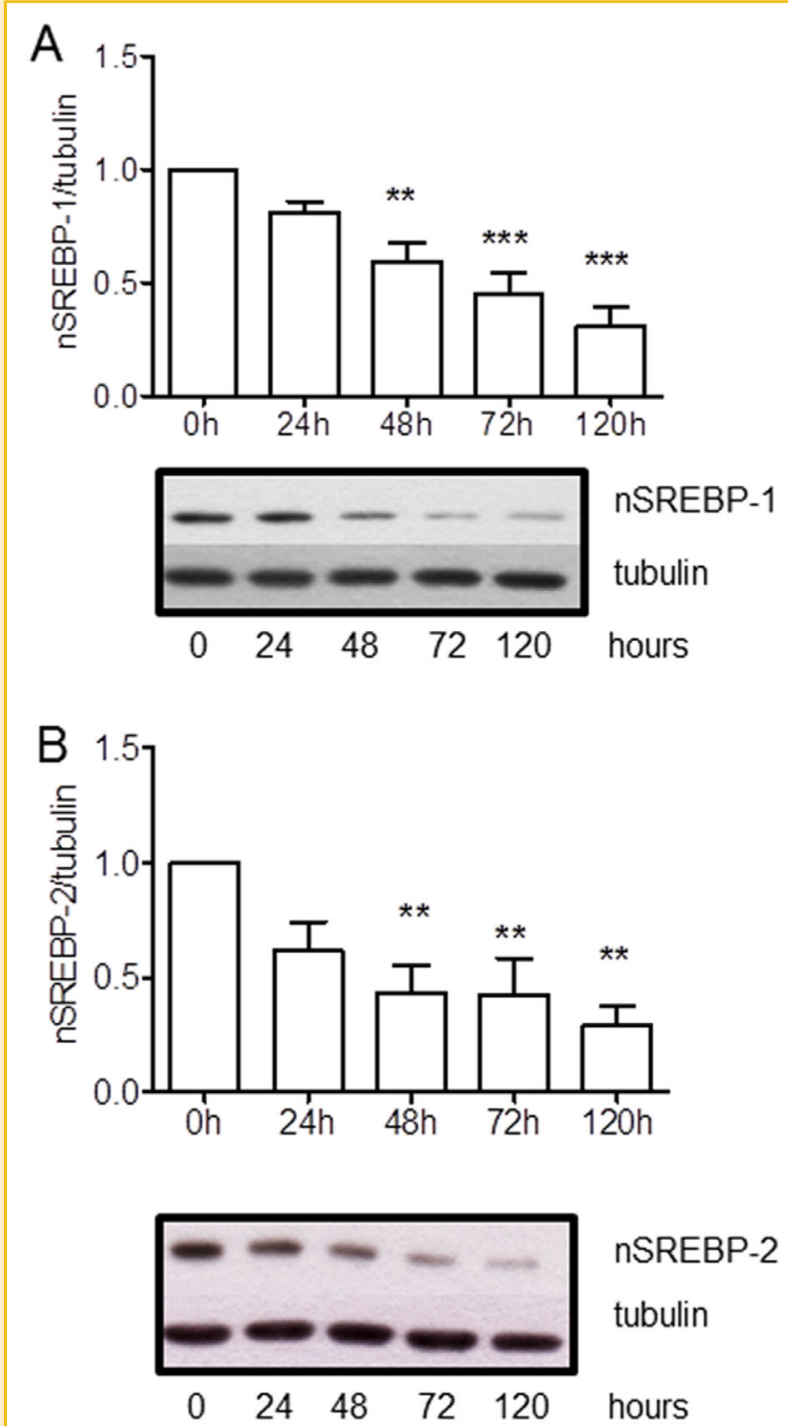

nSREBP-2

tubulin

hours

Fig. 4. SREBP-1 and SREBP-2 analysis, in differentiating N1E-115 mouse neuroblastoma. Panel A illustrates the transcriptionally active fragment of SREBP-1 ( $n$-SREBP-1) analysis, Panel B illustrates transcriptionally active fragment of SREBP-2 (SERBP-2) analysis. On the bottom are represented the immunoblots from a representative experiment. Similar results were obtained from three independent experiments for each protein considered. Average protein expression quantified as ratio between protein and tubulin. ${ }^{* *} P<0.01$, ${ }^{* * *} P<0.001$ versus $0 \mathrm{~h}$ as from one-way analysis of variance (ANOVA) followed by Tukey post-test. 


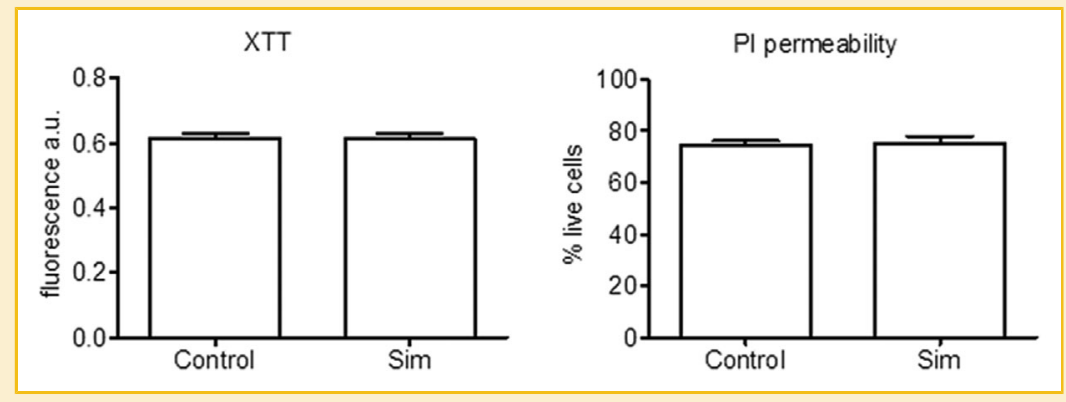

Fig. 5. Evaluation of cell viability in differentiating N1E-115 mouse neuroblastoma cells. Figure illustrates on the left XTT assay and on the right PI exclusion assay performed on N1E-115 cells induced to differentiate with $2 \%$ DMSO for $120 \mathrm{~h}$ in presence and in absence of $1 \mu \mathrm{M}$ simvastatin. For details see the main text.

induction of differentiation (Fig. 2 inset), indicating that the metabolic flux through the MVA pathway decreases. The MVA pathway is an important component of lipid homeostasis in cells together with the machinery that mediates cholesterol uptake. We therefore tested next, whether lipoprotein receptors were affected by DMSO-induced neuronal differentiation. The level of LDLr decreased, whereas the level of LRP1 was increased (Fig. 3A and B). The latter change was not surprising, because LRP1 is a prominent component of neurites [Kanekiyo and $\mathrm{Bu}, 2014$ ], whose growth is induced by DMSO. On the other hand, we also observed a decrease of
SRB1 at $75 \mathrm{kDa}$ (Fig. 3C), and interestingly, we observed at $72 \mathrm{~h}$ of treatment a band at $150 \mathrm{kDa}$ which may signify the dimerization of SRB-1 and a possible translocation of the protein complex on plasma membrane. The appearance of SRB-1 on the cell surface after $72 \mathrm{~h}$ of treatment was confirmed by live labeling with the antibody and subsequent flow cytometric analyses (Fig. 3D).

The expression of MVA enzymes, lipoprotein receptors, and other components controlling lipid homeostasis is regulated by two transcription factors, the so called SREBP-1 and -2 , which undergo cleavage and transfer to the nucleus upon declining lipid levels.

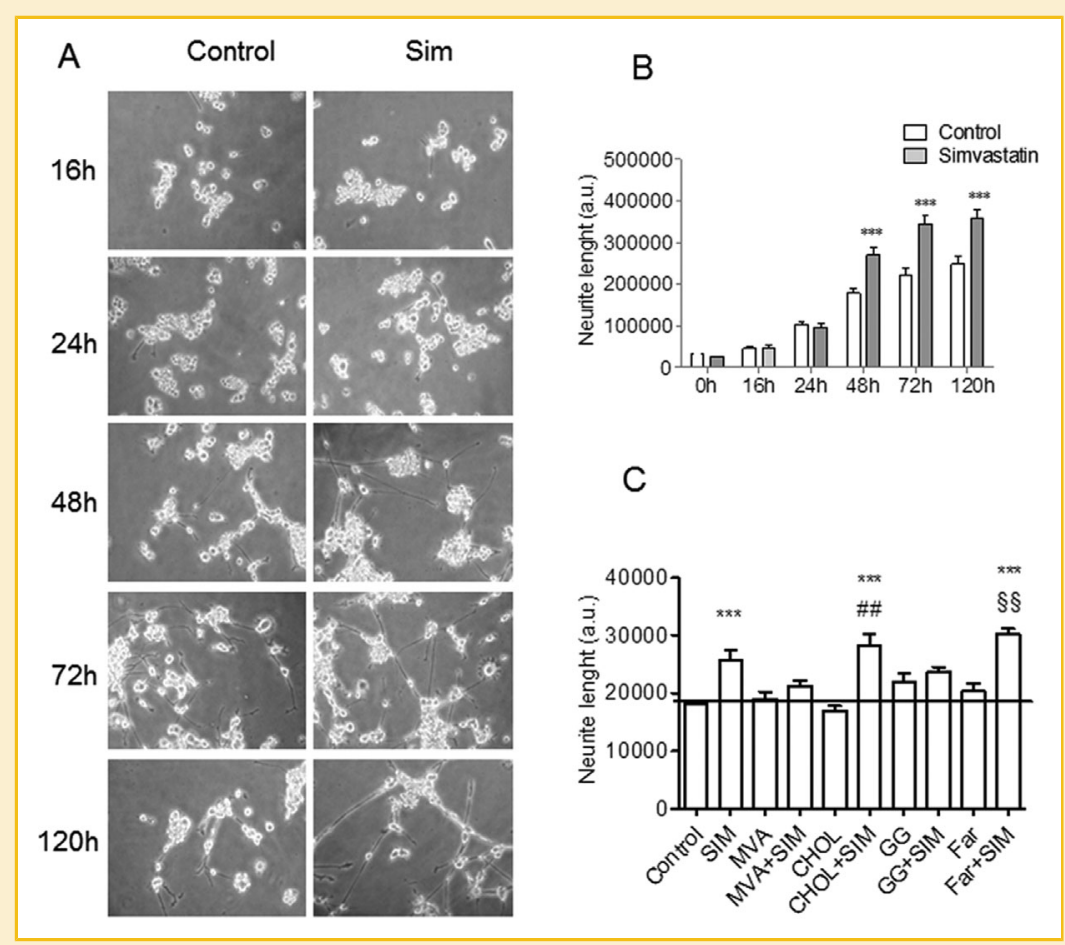

Fig. 6. Neurite elongation analysis of N1E-115 mouse neuroblastoma during DMSO-induced differentiation. Panel A shows representative pictures of "in vivo" cell detection under an Olympus CKX 41 microscope, equipped with a Leica DFC 420 camera. It represents the neurite elongation during DMSO-induced cell differentiation in presence and in absence of $1 \mu \mathrm{M}$ simvastatin starting from $0 \mathrm{~h}$ to $120 \mathrm{~h}$. Panel B shows the statistical analysis of neurite elongation performed on 10 randomly selected fields from three independent preparations. Panel C represents the neurite elongation analysis, at $120 \mathrm{~h}$ after the induction of the differentiation by DMSO, in presence and in absence of SIM or $\mathrm{SIM}+$ HMGR end products: MVA, cholesterol (CHOL), geranyl geraniol (GG), Farnesol (Far). All the compounds were administered at $1 \mu \mathrm{M}$. The analysis was performed on 10 randomly selected fields from three independent preparations. ${ }^{* *} P<0.001$ versus Control, ${ }^{\# \#} P<0.01$ versus $\mathrm{CHOL}$, ${ }^{\$ \S} P<0.01$ versus Far; as from one-way analysis of variance (ANOVA) followed by Tukey post-test. 
Immunoblotting revealed that the levels of transcriptionally active SREBP-1 and of SREBP-2 decreased during differentiation (Fig. 4).

Our results indicated that neuronal differentiation is accompanied by a decrease in MVA synthesis and predicted that a further decrease of MVA synthesis will accelerate neuronal differentiation. To test this hypothesis, we induced neuronal differentiation by DMSO in the presence or absence of simvastatin, a well-established HMGR inhibitor, at a concentration that was not toxic to neurons as indicated by XTT and Propidium Iodide exclusion test (Fig. 5). To determine the degree of neuronal differentiation, we measured neurite length. We observed that simvastatin treatment increased the length of neurites indicating that a decrease of MVA pathway promotes neuronal differentiation in our experimental model (Fig. 6A and B). We next tested, which end-product of MVA pathway mediated this effect. We induced neuronal differentiation in the presence of simvastatin and added MVA, cholesterol (CHOL), geranylgeranyiol (GG) or farnesol (Far) for $120 \mathrm{~h}$. As shown in Figure 6C, only MVA and GG prevented the simvastatin-induced increase of neurite outgrowth. Filipin staining of neurons treated or not with simvastatin demonstrated that cellular cholesterol content did not change (Fig. 7).

GG is required for the prenylation of GTP binding proteins and prominent targets are the Rho family GTPases. A prominent member of this family is RhoA, which negatively controls neurite outgrowth [Govek et al., 2011] and whose prenylation allows its translocation to the plasma membrane and its subsequent activation [Segatto et al., 2014b]. We tested whether simvastatin affected the RhoA content of the membrane fraction. As shown in Figure 8 simvastatin decreased the RhoA level in membrane lysates, and this effect was reverted by MVA and GG indicating that the neurite growth promoting effect of simvastatin was mediated, at least in part, via reduced isoprenylation of RhoA.

\section{DISCUSSION}

It is well known that neurons proliferate and then differentiate changing their morphology, outgrowing neurites and becoming functionally active. Here, we investigated the role of the MVA pathway during neuronal differentiation in mouse neuroblastoma N1E-115 cells, a valuable and widely used experimental model, which recapitulates key steps of neurite initiation and outgrowth [Shim et al., 2006].

We focused our attention on the protein network that controls the MVA pathway and in turn the cellular cholesterol homeostasis during neuronal differentiation. Intriguingly, HMGR activation decreased along the considered time points, suggesting a progressive reduction of cellular cholesterol synthesis during neuronal differentiation. This result is in good agreement with the hypothesis that during development, neurons decrease their cholesterol synthesis [Mauch et al., 2001; Pfrieger and Ungerer, 2011]. The decrease of HMGR activity is due to decline of the total protein levels and independent from phosphorylation/dephosphorylation mechanisms. The decrease of both the transcription factors (SREBP1 and -2) not only accounts for the reduced HMGR protein expression, but also for the significant fall in LDLr [Horton, 2002] and for the increased LRP1 levels [Llorente-Cortes et al., 2006; Llorente-Cortes et al., 2007]. Regarding SRB-1 we made interesting observations.
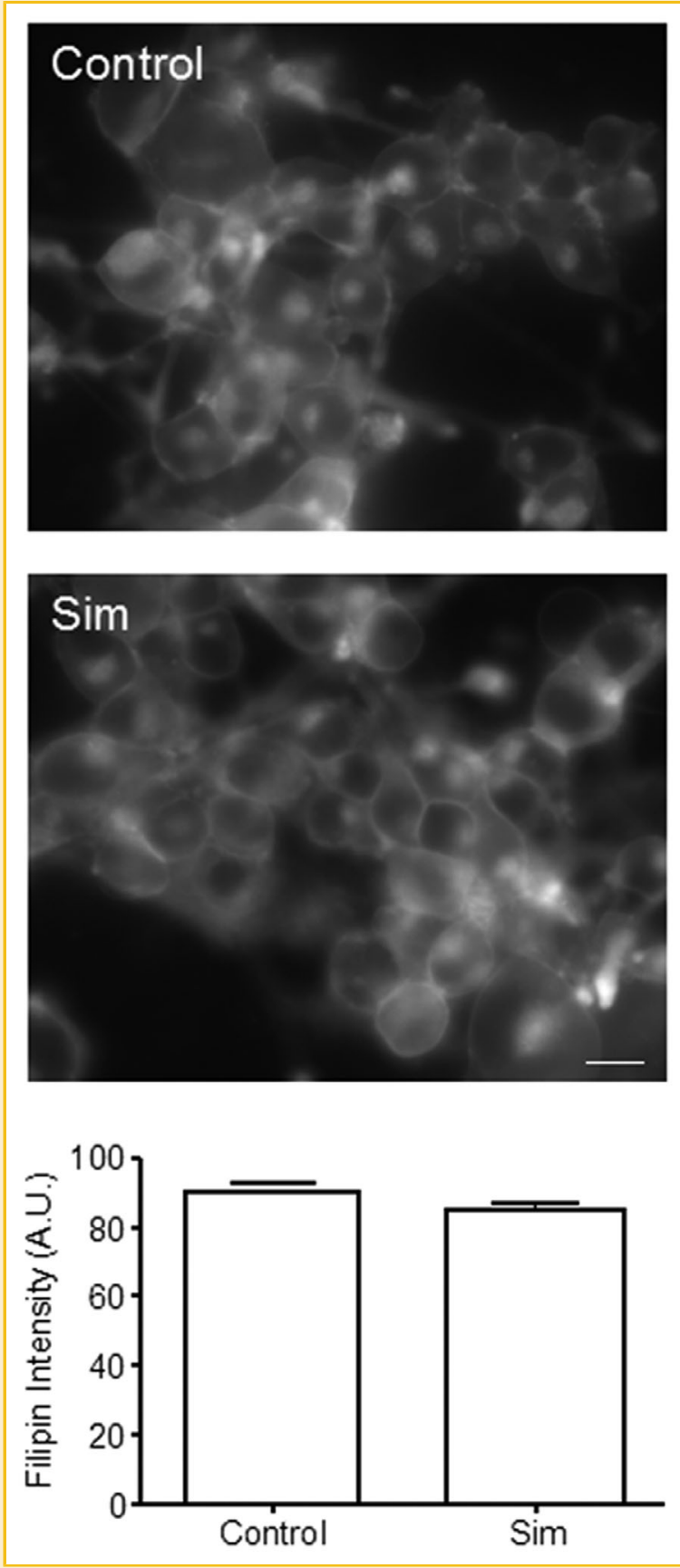

Fig. 7. Cholesterol content evaluation in differentiating N1E-115 mouse neuroblastoma. N1E-115 cells were treated or not with $1 \mu \mathrm{M} \mathrm{Sim}$, for $120 \mathrm{~h}$ after DMSO administration. Cells were fixed with $4 \%$ paraformaldehyde and stained with filipin. Representative pictures of the filipin staining are shown on the top. On bottom, data analysis of filipin intensity measured as described in the main text is illustrated.

During differentiation the protein dimerizes leading to the appearance of a $150 \mathrm{kDa}$ band. The dimerization represents a physiological event, since the protein is functional when expressed on the cell surface as a dimer [Gaidukov et al., 2011]. Indeed, our flow cytometric analysis, performed in live cells, does not show any SRB-1 signal on membrane surfaces of undifferentiated cells $(0 \mathrm{~h})$ 


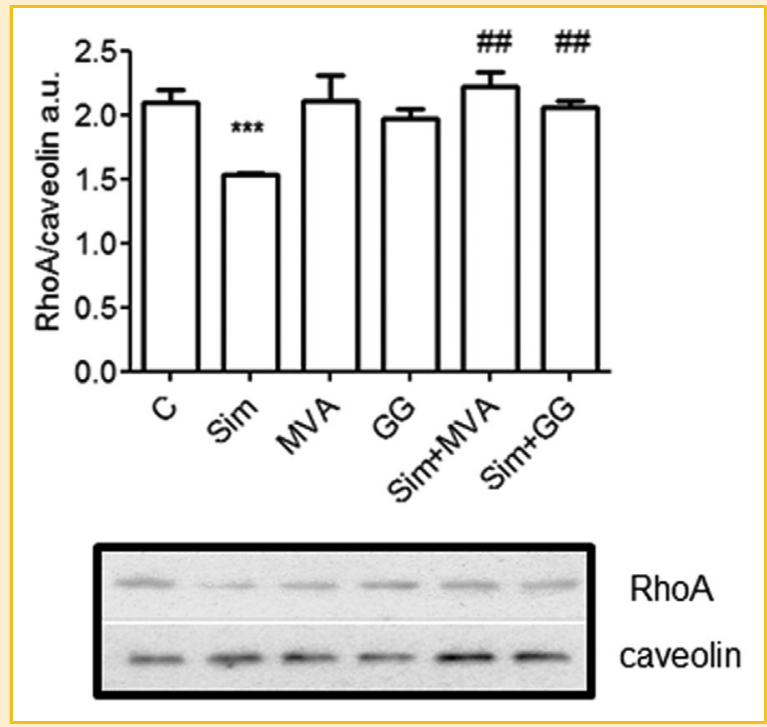

Fig. 8. RhoA analysis in undifferentiated and differentiated N1E-115 mouse neuroblastoma in presence of Sim and HMGR end-products. N1E-115 cells were treated with $1 \mu \mathrm{M}$ Sim, or $1 \mu \mathrm{M}$ MVA, or $1 \mu \mathrm{M} \mathrm{GG}$, or Sim + MVA, or $\mathrm{Sim}+\mathrm{GG}$ for $120 \mathrm{~h}$ after DMSO administration. Then cell membranes were prepared as illustrated in the main text. Bottom of the figure shows an immunoblot from a representative experiment. Similar results were obtained from three independent experiments. Average protein expression is represented on the top and quantified as ratio between RhoA and caveolin. The size of RhoA is $21 \mathrm{kDa}$, the size of caveolin is $22 \mathrm{kDa}$. ${ }^{* * *} P<0.001$ versus $C_{1}{ }^{\# \#} P<0.01$ versus $\mathrm{Sim}$ as from one-way analysis of variance (ANOVA) followed by Tukey post-test.

whereas an increase of fluorescence intensity is detectable at $72 \mathrm{~h}$ in accordance with the appearance of the $150 \mathrm{kDa}$ SRB- 1 in Western blot analysis. Thus, since cholesterol synthesis decreases during neuronal differentiation, cells could supply their cholesterol needs through the increase of both LRP1 and the functional SRB-1. In our opinion SR-B1 dimerization may be considered a new marker of neuronal differentiation.

Our results show that the pharmacological inhibition of MVA pathway increases the rate of neurite outgrowth. These results are in good agreement with those obtained by other research groups [Maltese and Sheridan, 1985; Sato-Suzuki and Murota, 1996; Holmberg et al., 2006; Pooler et al., 2006; Raina et al., 2013]. These effects are completely prevented by MVA administration, indicating that simvastatin-induced neurite elongation depends on the specific HMGR inhibition and not by an effect exerted by simvastatin per se. Beside cholesterol, MVA is the precursor of isoprenoids such as GG or Far that are required for the prenylation and the subsequent activation of different proteins. Our finding that only GG prevented the simvastatin-induced neurite outgrowth, suggests that geranylgeranylated proteins, rather than farnesylated ones or cholesterol, promote neurite formation, and elongation. The intracellular cholesterol content as measured by filipin did not change in differentiating cells both in presence and in absence of simvastatin. Moreover, we found that simvastatin significantly reduced membrane-associated RhoA levels in N1E-115 cells. G Geranylgeranylation of RhoA is essential for membrane translocation and the activation of its signaling functions [Seasholtz et al., 1999]. This includes the actomyosin-based contractility of neurites and the disassembly of microtubules and intermediate filaments leading to neurite retraction [Hirose et al., 1998]. We therefore conclude that simvastatin promotes neurite elongation by preventing the activation of the negative regulator RhoA.

Taken together our presented data indicate that the decrease of the MVA pathway is fundamental for neurite outgrowth and in turn neuronal differentiation. The progressive decrease in the activation of isoprenoid/cholesterol metabolic pathways is a physiological feature in differentiating neurons, and assumes that any interference in the modulation of this metabolic pathway can alter neuronal function. In neuropathologies caused by disturbed neuronal development, statin treatment may help to improve the neurological and metabolic symptoms [Wang, 2014].

\section{ACKNOWLEDGMENTS}

This work was supported by grants from the University of "Roma Tre" CLA 2013-2015 to V.P. We thank M. Perraut for help with cytochemical staining.

\section{REFERENCES}

Amir RE, Van den Veyver IB, Wan M, Tran CQ, Francke U, Zoghbi HY. 1999. Rett syndrome is caused by mutations in X-linked MECP2, encoding methylCpG-binding protein 2. Nat Genet 23:185-188.

Baytan SH, Alkanat M, Okuyan M, Ekinci M, Gedikli E, Ozeren M, Akgun A. 2008. Simvastatin impairs spatial memory in rats at a specific dose level. Tohoku J Exp Med 214:341-349.

Brown MS, Goldstein JL. 1980. Multivalent feedback regulation of HMG CoA reductase, a control mechanism coordinating isoprenoid synthesis and cell growth. J Lipid Res 21:505-517.

Buchovecky CM, Turley SD, Brown HM, Kyle SM, McDonald JG, Liu B, Pieper AA, Huang W, Katz DM, Russell DW, Shendure J, Justice MJ. 2013. A suppressor screen in Mecp2 mutant mice implicates cholesterol metabolism in Rett syndrome. Nat Genet 45:1013-1020.

Chaudhury S, Sharma V, Kumar V, Nag TC, Wadhwa S. 2015. Activitydependent synaptic plasticity modulates the critical phase of brain development. Brain Dev. In press.

Clejan S, Dotson RS, Wolf EW, Corb MP, Ide CF. 1996. Morphological differentiation of N1E-115 neuroblastoma cells by dimethyl sulfoxide activation of lipid second messengers. Exp Cell Res 224:16-27.

da Silva JS, Dotti CG. 2002. Breaking the neuronal sphere: Regulation of the actin cytoskeleton in neuritogenesis. Nat Rev Neurosci 3:694-704.

Douma TN, Borre Y, Hendriksen H, Olivier B, Oosting RS. 2011. Simvastatin improves learning and memory in control but not in olfactory bulbectomized rats. Psychopharmacology (Berl) 216:537-544.

Espenshade PJ, Hughes AL. 2007. Regulation of sterol synthesis in eukaryotes. Annu Rev Genet 41:401-427.

Fan QW, Yu W, Gong JS, Zou K, Sawamura N, Senda T, Yanagisawa K, Michikawa M. 2002. Cholesterol-dependent modulation of dendrite outgrowth and microtubule stability in cultured neurons. J Neurochem 80:178-190.

Gaidukov L, Nager AR, Xu S, Penman M, Krieger M. 2011. Glycine dimerization motif in the $\mathrm{N}$-terminal transmembrane domain of the high density lipoprotein receptor SR-BI required for normal receptor oligomerization and lipid transport. J Biol Chem 286:18452-18464.

Govek EE, Hatten ME, Van Aelst L. 2011. The role of Rho GTPase proteins in CNS neuronal migration. Dev Neurobiol 71:528-553. 
Hanson MG, Landmesser LT. 2004. Normal patterns of spontaneous activity are required for correct motor axon guidance and the expression of specific guidance molecules. Neuron 43:687-701.

Hill DS, Cabrera R, Wallis Schultz D, Zhu H, Lu W, Finnell RH, Wlodarczyk BJ. 2015. Autism-like behavior and epigenetic changes associated with autism as consequences of in utero exposure to environmental pollutants in a mouse model. Behav Neurol 2015:426263.

Hirose M, Ishizaki T, Watanabe N, Uehata M, Kranenburg O, Moolenaar WH, Matsumura F, Maekawa M, Bito H, Narumiya S. 1998. Molecular dissection of the Rho-associated protein kinase (p160ROCK)-regulated neurite remodeling in neuroblastoma N1E-115 cells. J Cell Biol 141:1625-1636.

Holmberg E, Nordstrom T, Gross M, Kluge B, Zhang SX, Doolen S. 2006. Simvastatin promotes neurite outgrowth in the presence of inhibitory molecules found in central nervous system injury. J Neurotrauma 23:1366-1378.

Horton JD. 2002. Sterol regulatory element-binding proteins: Transcriptional activators of lipid synthesis. Biochem Soc Trans 30:1091-1095.

Jensen RA. 1994. Autism and the chemical connection. J Autism Dev Disord 24:785-787.

Kanekiyo T, Bu G. 2014. The low-density lipoprotein receptor-related protein 1 and amyloid-beta clearance in Alzheimer's disease. Front Aging Neurosci 6:93.

Kilic FS, Ozatik Y, Kaygisiz B, Baydemir C, Erol K. 2012. Acute antidepressant and anxiolytic effects of simvastatin and its mechanisms in rats. Neurosciences (Riyadh) 17:39-43.

Kim WY, Gonsiorek EA, Barnhart C, Davare MA, Engebose AJ, Lauridsen H, Bruun D, Lesiak A, Wayman G, Bucelli R, Higgins D, Lein PJ. 2009. Statins decrease dendritic arborization in rat sympathetic neurons by blocking RhoA activation. J Neurochem 108:1057-1071.

Lee D, Kim KY, Shim MS, Kim SY, Ellisman MH, Weinreb RN, Ju WK. 2014. Coenzyme Q10 ameliorates oxidative stress and prevents mitochondrial alteration in ischemic retinal injury. Apoptosis 19:603-614.

Llorente-Cortes V, Costales P, Bernues J, Camino-Lopez S, Badimon L. 2006. Sterol regulatory element-binding protein-2 negatively regulates low density lipoprotein receptor-related protein transcription. J Mol Biol 359:950-960.

Llorente-Cortes V, Royo T, Otero-Vinas M, Berrozpe M, Badimon L. 2007. Sterol regulatory element binding proteins downregulate LDL receptorrelated protein (LRP1) expression and LRP1-mediated aggregated LDL uptake by human macrophages. Cardiovasc Res 74:526-536.

Lowry OH, Rosebrough NJ, Farr AL, Randall RJ. 1951. Protein measurement with the Folin phenol reagent. J Biol Chem 193:265-275.

Maltese WA, Sheridan KM. 1985. Differentiation of neuroblastoma cells induced by an inhibitor of mevalonate synthesis: Relation of neurite outgrowth and acetylcholinesterase activity to changes in cell proliferation and blocked isoprenoid synthesis. J Cell Physiol 125:540-558.

Martin MG, Pfrieger F, Dotti CG. 2014. Cholesterol in brain disease: Sometimes determinant and frequently implicated. EMBO Rep 15: 1036-1052.

Mauch DH, Nagler K, Schumacher S, Goritz C, Muller EC, Otto A, Pfrieger FW. 2001. CNS synaptogenesis promoted by glia-derived cholesterol. Science 294:1354-1357.

Nuttall JR. 2015. The plausibility of maternal toxicant exposure and nutritional status as contributing factors to the risk of autism spectrum disorders. Nutr Neurosci. [Epub ahead of print] in press.

Oh JE, Karlmark Raja K, Shin JH, Pollak A, Hengstschlager M, Lubec G. 2006. Cytoskeleton changes following differentiation of N1E-115 neuroblastoma cell line. Amino Acids 31:289-298.

Orth M, Bellosta S. 2012. Cholesterol: Its regulation and role in central nervous system disorders. Cholesterol 2012:292598.
Pallottini V, Martini C, Cavallini G, Bergamini E, Mustard KJ, Hardie DG, Trentalance A. 2007. Age-related HMG-CoA reductase deregulation depends on ROS-induced p38 activation. Mech Ageing Dev 128:688-695.

Pfrieger FW, Ungerer N. 2011. Cholesterol metabolism in neurons and astrocytes. Prog Lipid Res 50:357-371.

Pooler AM, Xi SC, Wurtman RJ. 2006. The 3-hydroxy-3-methylglutaryl coenzyme A reductase inhibitor pravastatin enhances neurite outgrowth in hippocampal neurons. J Neurochem 97:716-723.

Prendergast GC, Oliff A. 2000. Farnesyltransferase inhibitors: Antineoplastic properties, mechanisms of action, and clinical prospects. Semin Cancer Biol 10:443-452.

Raina V, Gupta S, Yadav S, Surolia A. 2013. Simvastatin induced neurite outgrowth unveils role of cell surface cholesterol and acetyl CoA carboxylase in SH-SY5Y cells. PLoS ONE 8:e74547.

Rodrigues JM, Luis AL, Lobato JV, Pinto MV, Faustino A, Hussain NS, Lopes MA, Veloso AP, Freitas M, Geuna S, Santos JD, Mauricio AC. 2005. Intracellular $\mathrm{Ca} 2+$ concentration in the N1E-115 neuronal cell line and its use for peripheric nerve regeneration. Acta Med Port 18:323-328.

Sah VP, Seasholtz TM, Sagi SA, Brown JH. 2000. The role of Rho in G proteincoupled receptor signal transduction. Annu Rev Pharmacol Toxicol 40:459-489.

Samuel F, Reddy J, Kaimal R, Segovia V, Mo H, Hynds DL. 2014. Inhibiting geranylgeranylation increases neurite branching and differentially activates cofilin in cell bodies and growth cones. Mol Neurobiol 50:49-59.

Sato-Suzuki I, Murota S. 1996. Simvastatin inhibits the division and induces neurite-like outgrowth in PC12 cells. Neurosci Lett 220:21-24.

Schulz JG, Bosel J, Stoeckel M, Megow D, Dirnagl U, Endres M. 2004. HMGCoA reductase inhibition causes neurite loss by interfering with geranylgeranylpyrophosphate synthesis. J Neurochem 89:24-32.

Seasholtz TM, Majumdar M, Brown JH. 1999. Rho as a mediator of G proteincoupled receptor signaling. Mol Pharmacol 55:949-956.

Segatto M, Leboffe L, Trapani L, Pallottini V. 2014. Cholesterol homeostasis failure in the brain: Implications for synaptic dysfunction and cognitive decline. Curr Med Chem 21:2788-2802.

Segatto M, Manduca A, Lecis C, Rosso P, Jozwiak A, Swiezewska E, Moreno S, Trezza V, Pallottini V. 2014. Simvastatin treatment highlights a new role for the isoprenoid/cholesterol biosynthetic pathway in the modulation of emotional reactivity and cognitive performance in rats. Neuropsychopharmacology 39:841-854.

Segatto M, Trapani L, Di Tunno, I, Sticozzi C, Valacchi G, Hayek J, Pallottini V. 2014. Cholesterol metabolism is altered in Rett syndrome: A study on plasma and primary cultured fibroblasts derived from patients. PLoS ONE 9: e104834.

Shim KS, Rosner M, Freilinger A, Lubec G, Hengstschlager M. 2006. Bach2 is involved in neuronal differentiation of N1E-115 neuroblastoma cells. Exp Cell Res 312:2264-2278.

Trapani L, Segatto M, Ascenzi P, Pallottini V. 2011. Potential role of nonstatin cholesterol lowering agents. IUBMB Life 63:964-971.

Valenza M, Marullo M, Di Paolo E, Cesana E, Zuccato C, Biella G, Cattaneo E. 2015. Disruption of astrocyte-neuron cholesterol cross talk affects neuronal function in Huntington's disease. Cell Death Differ 22:690-702.

Villarroel-Campos D, Gastaldi L, Conde C, Caceres A, Gonzalez-Billault C. 2014. Rab-mediated trafficking role in neurite formation. J Neurochem 129:240-248

Wang H. 2014. Lipid rafts: A signaling platform linking cholesterol metabolism to synaptic deficits in autism spectrum disorders. Front Behav Neurosci 8:104.

While A, Keen L. 2010. The effects of statins on mood: A review of the literature. Eur J Cardiovasc Nurs 11:85-96. 